\title{
Persepi Wisatawan Terhadap Wisata Kuliner Ikan Mujair Nyat- Nyat di Desa Kedisan, Kecamatan Kintamani, Kabupaten Bangli
}

\author{
I Made Purwa Dana Atmaja* \\ Program Studi Manajemen Tata Boga, Sekolah Tinggi Pariwisata Nusa Dua Bali
}

\section{A R T I C L E I N F O}

Article history:

Received 19 May 2018

Received in revised form 10 June 2018

Accepted 28 July 2018

Available online 29 August 2018

\section{Kata Kunci:}

Persepsi wisatawan, kuliner, mujair nyat-nyat.

Keywords:

Tourist perception, culinary, real tilapia. product,

spectrophotometric

\begin{abstract}
A B S T R A K
Tujuan penelitian ini adalah untuk mengetahui dan mendeskripsikan persepsi wisatawan terhadap wisata kuliner ikan mujair nyat-nyat di Desa Kedisan, Kecamatan Kintamani, Kabupaten Bangli. Metode penelilitian yang digunakan adalah metode kuantitatif. Data dikumpulkan dengan cara observasi, wawancara, dan dokumentasi. Observasi. Setelah dipaparkan nilai dengan skala likert, data dianalisis menggunakan teknik deskriptif kuantitatif, yaitu metode yang menguraikan berbagai data yang terkumpul secara logis sehingga dapat ditarik suatu kesimpulan serta didukung analisis rata-rata terimbang untuk menjawab perumusan masalah. Berdasarkan hasil pembahasan dan analisis data pada bab sebelumnya dapat diambil kesimpulan bahwa persepsi wisatawan terhadap kualitas makanan ikan mujair nyat-nyat di Desa Kedisan, Kecamatan Kintamani, Kabupaten Bangli adalah baik, begitu pula dengan sumber daya manusia dan pelayanannya, namun cukup dari segi hygiene dan sanitasi.
\end{abstract}

\section{A B S T R A C T}

The purpose of this study was to find out and describe the perceptions of tourists on real mujair fish culinary tourism in Kedisan Village, Kintamani District, Bangli Regency. The research method used is a quantitative method. Data is collected by observation, interviews, and documentation. Observation. After describing the value with the Likert scale, the data were analyzed using quantitative descriptive techniques, namely methods that describe various data collected logically so that a conclusion can be drawn and supported by a balanced average analysis to answer the problem formulation. Based on the results of the discussion and data analysis in the previous chapter, it can be concluded that tourists' perceptions of the quality of food of real tilapia fish in Kedisan Village, Kintamani District, Bangli Regency are good, as well as human resources and services, but sufficient in terms of hygiene and sanitation..

Copyright (C) Universitas Pendidikan Ganesha. All rights reserved.

\footnotetext{
* Corresponding author.

E-mail addresses: purwadanaatmajaa@gmail.com (I Made Purwa Dana Atmaja)
} 


\section{Pendahuluan}

Pariwisata merupakan suatu kebutuhan manusia dari jaman dahulu. Dengan banyaknya kegiatan yang kita lakukan setiap hari akan menimbulkan rasa jenuh didalam diri kita, oleh karena itu, kita membutuhkan suasana baru dengan cara melakukan perjalanan untuk menikmati keindahan alam. Sebagaimana kita ketahui Indonesia merupakan negara yang memiliki kekayaan sumber daya alam yang melimpah dan keanekaragaman yang beragam. Indonesia memiliki banyak tempat wisata yang sangat berpotensi apabila dikembangkan, sebagai contoh banyak tempat wisata yang dapat kita temui di Bali. Hal tersebut menjadi daya tarik wisatawan, baik wisatawan asing maupun wisatawan lokal. Karakteristik alam dan tata nilai kehidupan masyarakat sangat memungkinkan untuk dikembangkan sebagai potensi wisata. Karena itu pariwisata saat ini sedang gencar-gencarnya dipromosikan. Tujuannya adalah membuat orang dari berbagai tempat untuk datang ke daerah yang dipromosikan dan selanjutnya meyakinkan para wisatawan atas fakta bahwa daerah yang dipromosikan memiliki daya tarik yang sulit untuk dilewatkan. Contoh daya tarik wisata antara lain wisata rekreasi, wisata budaya, wisata belanja, wisata kuliner dan lain-lain.

Wisata kuliner saat ini menjadi jenis wisata yang sangat banyak dampaknya bagi perkembangan sebuah daerah (Stowe \& Johnson, 2010). Kuliner merupakan elemen penting dari citra suatu daerah untuk kepariwisataan, ini menunjukan bahwa ada hubungan simbiosis antara makanan dengan industry pariwisata. Lebih penting lagi, makanan diakui sebagai alat promosi destinasi wisata yang efektif (Hjalager \& Richards, 2002). Salah satu nilai penting dalam wisata kuliner ini adalah menumbuh kembangkan potensi makanan asli daerah yang mulai tergeser oleh produk-produk asing ataupun berorientasi makanan asing. Untuk itu perlu dibuat sebuah usaha untuk meningkatkan potensi ekonomis ini dengan memberikan sentuhan atau dukungan untuk dapat menarik wisatawan lokal atau asing dalam menikmati kuliner asli daerah.

Bali merupakan salah satu daerah yang menyediakan berbagai makanan tradisional khas daerahnya. Maka dari itu banyak wisatawan yang datang ke daerah ini. Dengan banyaknya kunjungan wisatawan yang datang ke Bali maka banyak produsen yang berlomba-lomba untuk menciptakan makanan/kuliner dengan rasa dan jenis yang berbeda tanpa menghilangkan keaslian makanan tersebut. Banyak wisatawan yang menyukai makanan khas Bali karena harganya yang terjangkau dan memiliki ciri khas tersendiri dalam setiap masakannya. Ada beberapa makanan yang terkenal di Pulau Dewata ini yang biasanya dicari oleh wisatawan seperti olahan berbahan ayam, babi, bebek, mujair dan lain-lain. Ikan mujair merupakan salah satu ikan yang banyak dibudidayakan di danau Batur, Kintamani

Kintamani yang terkenal dengan Danau Batur yang sangat indah. Perairan Danau Batur memberikan berkah berupa hasil ikan air tawar seperti ikan nila (oreochromis niloticus), ikan nyalian poleng (rasbora lateristriata), belut (monopterus albus), ikan mujair (oreochromis mossambicus) dan lainnya yang sangat menggoda untuk diolah, terutama bagi mereka yang mencintai cita rasa khas Bali. Di Kintamani banyak sekali terdapat restaurant atau rumah makan yang menyediakan Ikan Mujair sebagai menu andalan mereka, salah satu olahan ikan mujair yang disukai wisatawan adalah mujair nyat-nyat.

Mujair Nyat-nyat adalah salah satu primadona kuliner di Kintamani yang berhasil menarik perhatian wisatawan. Diolah dengan cara di nyat-nyat bersama racikan bumbu khas Bali (Base Genep), menjadikan hidangan ini kaya akan cita rasa. Perpaduan rasa pedas, sedikit asam dan gurihnya ikan serta wangi bumbu Bali yang unik benar-benar menciptakan olahan yang sempurna disajikan dengan nasi panas, plecing kangkung, sambal matah dan kacang goreng. Nyat-nyat merupakan metode masakan khas Bali dimana bahan makanan dimatangkan dengan cara dimasak dengan air dan bumbu-bumbu sampai airnya menyusut atau tersisa sedikit. Mujair nyat-nyat sangat mudah dijumpai di Kintamani karena memang makanan ini merupakan makanan khas Kintamani. Namun, dari hasil survei yang penulis lakukan berupa observasi dan wawancara di 5 warung ikan mujair nyat-nyat, diketahui bahwa sebagian besar pengunjung adalah wisatawan domestik, sedangkan wisatawan asing sedikit yang berkunjung ke warung ikan mujair nyat-nyat tersebut. Pengelola warung makan belum mengetahui tentang alasan hal tersebut dan ditambah lagi belum adanya penelitian tentang persepsi wisatawan terhadap wisata kuliner ikan mujair nyat-nyat di Desa Kedisan, Kecamatan Kintamani, Kabupaten Bangli. Sangat penting bagi pemasar destinasi kuliner untuk mengetahui tanggapan atau persepsi konsumennya.

Persepsi merupakan kesan yang diperoleh oleh individu melalui panca indera kemudian dianalisa, diinterpretasi dan kemudian dievaluasi sehingga individu tersebut memperoleh makna (Robbins 2003 : 97). Purwodarminto (1990 : 759) menambahkan, persepsi adalah tanggapan langsung dari suatu serapan atau proses seseorang mengetahui beberapa hal melalui pengindraan. Menurut sebuah studi yang dirilis oleh Asosiasi Perjalanan AS, satu-seperempat dari seluruh pelancong rekreasi mengatakan, makanan adalah faktor penting ketika mereka memilih tujuan wisata. Oleh karena itu, penting bagi pengusaha di bidang kuliner untuk mengetahui persepsi target konsumen tentang kuliner dan bagaimana 
mempengaruhi niat mereka untuk mengunjungi melalui strategi pemasaran yang efektif. Dari uraian latar belakang diatas, maka penulis mengidentifikasikan beberapa permasalahan, antara lain: (1) Sebagian besar pengunjung adalah wisatawan domestik, sedangkan wisatawan asing sedikit yang berkunjung ke warung ikan mujair nyat-nyat di Desa Kedisan, Kecamatan Kintamani, Kabupaten Bangli; (2) Pengelola warung makan ikan mujair nyat-nyat belum mengetahui mengenai alasan hal tersebut; (3) Belum adanya penelitian tentang persepsi wisatawan terhadap wisata kuliner ikan mujair nyat-nyat di Desa Kedisan, Kecamatan Kintamani, Kabupaten. Adapun tujuan dari penelitian ini adalah untuk mengetahui dan mendeskripsikan persepsi wisatawan terhadap wisata kuliner ikan mujair nyat-nyat di Desa Kedisan, Kecamatan Kintamani, Kabupaten Bangli.

\section{Metode}

Objek penelitian adalah sasaran ilmiah untuk mendapatkan data dengan tujuan dan kegunaan tertentu tentang suatu hal objektif, valid dan reliable tentang suatu hal veriable tertentu (Sugiyono 2010: 13). Dalam penelitian ini yang menjadi objek penelitian adalah Persepsi wisatawan terhadap olahan ikan mujair nyat-nyat di Kintamani. Sesuai dengan judul yang penulis angkat pada penelitian ini, maka penulis mengambil lokasi penelitian di Desa Kedisan, Kecamatan Kintamani, Kabupaten Bangli.

Sumber data dalam penelitian adalah subjek darimana data itu diperoleh (Arikunto 2010: 172). Adapun sumber data dalam penelitian ini adalah sebagai berikut.

a. Peneliti, dimana data diperoleh dengan cara observasi di tempat penelitian berupa pengamatan dan pencatatan suatu fenomena secara sistematis.

b. Pemilik rumah makan, data yang diperoleh dari pemilik rumah makan berupa data hasil wawancara mengenai kunjungan wisatawan ke rumah makan ikan mujair nyat-nyat di Desa Kedisan, Kecamatan Kintamani, Kabupaten Bangli. Selain itu, pemilik rumah makan juga memberikan data berupa resep dan cara pembuatan ikan mujair nyat-nyat khas Desa Kedisan.

c. Pengunjung atau wisatawan, dalam hal ini pengunjung diberikan kuesioner yang berisikan tentang persepsi mereka terhadap ikan mujair nyat-nyat kemudian kuesioner tersebut direkap dan menghasilkan data mengenai Persepsi Wisatawan terhadap Ikan Mujair Nyat-Nyat di Desa Kedisan, Kecamatan Kintamani, Kabupaten Bangli.

Dari 3 sumber diatas, data yang diperoleh adalah data primer dan data sekunder. Data Primer adalah data yang diperoleh atau dikumpulkan langsung di lapangan oleh orang yang melakukan penelitian atau yang bersangkutan yang memerlukannya (Hasan 2002: 82). Sedangkan Data Sekunder adalah data yang diperoleh atau dikumpulkan oleh orang yang melakukan penelitian dari sumber-sumber yang telah ada (Hasan 2002: 58).

Data penelitian ini terdiri atas data kualitatif dan kuantitatif. Data kualitatif adalah data yang berupa non angka, seperti kalimat-kalimat atau catatan , foto, rekaman suara dan gambar (Mukhtar 2013 : 103). Dalam penelitian ini data kualitatif berupa hasil kuisioner tentang persepsi wisatawan terhadap ikan mujair nyat-nyat, dan hasil wawancara terhadap pemilik rumah makan terkait dengan jumlah kunjungan wisatawan ke warung ikan mujair nyat-nyat di Desa Kedisan, Kecamatan Kintamani, Kabupaten Bangli. Data kuantitatif adalah jenis data yang dapat diukur atau dihitung secara langsung, yang berupa informasi atau penjelasan yang dinyatakan dengan bilangan atau berbentuk angka (Sugiyono 2010 : 15). Dalam penelitian ini data kuantitatif berupa data jumlah kunjungan wisatawan ke warung ikan mujair nyat-nyat di Desa Kedisan, Kecamatan Kintamani, Kabupaten Bangli.

Pengumpulan data dilakukan memalui proses observasi, wawancara, dan dokumentasi. Observasi (Arifin, 2011) adalah suatu proses pengamatan dan pencatatan secara sistematis, logis, objektif dan rasional mengenai berbagai fenomena, baik dalam situasi yang sebenarnya maupun dalam situasi buatan untuk mencapai tujuan tertentu. Observasi dalam hal ini berupa pengamatan kunjungan wisatawan di rumah makan ikan mujair nyat-nyat di Desa Kedisan, Kecamatan Kintamani, Kabupaten Bangli. Wawancara adalah proses memperoleh keterangan untuk tujuan penelitian dengan cara Tanya jawab sambil bertatap muka antara pewawancara dengan si penjawab atau responden (Nazir 1998). Dalam penelitian ini wawancara berupa pertanyaan-pertanyaan kepada pemilik warung atau rumah makan mengenai jumlah kunjungan wisatawan di warung ikan mujair nyat-nyat di Desa Kedisan, Kecamatan Kintamani, Kabupaten Bangli. Kuesioner adalah teknik pengumpulan data yang dilakukan dengan cara memberi bebrapa pertanyaan kepada responden untuk dijawabnya, dapat diberikan secara langsung atau melalui internet. Jenis angket ada dua yaitu tertutup dan terbuka. Kuesioner yang digunakan dalam penelitian ini adalah kuisioner tertutup yakni kuesioner yang sudah disediakan jawabannya, sehingga responden tinggal memilih dan menjawab secara langsung (Sugiyono, 2008: 142). Dalam hal ini kuesioner ditujukan kepada wisatawan yang mengkonsumsi ikan mujair nyat-nyat di Desa Kedisan, Kecamatan Kintamani, Kabupaten Bangli mengenai persepsi mereka terhadap makanan tersebut. Dokumentasi atau 
dokumen merupakan catatan peristiwa yang sudah berlalu. Dokumen bisa berbentuk tulisan, gambar, atau karya-karya monumental dari seseorang (Sugiyono 2013 : 240). Dalam hal ini dokumentasi berupa foto-foto proses penelitian dari persepsi wisatawan terhadap wisata kuliner ikan mujair nyat-nyat, dan wawancara penulis dengan pemilik warung ikan mujair nyat-nyat di Desa Kedisan, Kecamatan Kintamani, Kabupaten Bangli.

Data dari kuesioner yang diperoleh akan dianalisis berdasarkan skala likert. Menurut Kennear (dalam Umar, 2005: 69) skala likert berhubungan dengan pernyataan tentang sikap seseorang terhadap sesuatu, misalnya sangat kurang baik, kurang, cukup, baik, dan sangat baik. Setelah dipaparkan nilai dengan skala likert, data dianalisis menggunakan teknik deskriptif kuantitatif, yaitu metode yang menguraikan berbagai data yang terkumpul secara logis sehingga dapat ditarik suatu kesimpulan serta didukung analisis rata-rata terimbang untuk menjawab perumusan masalah. Dalam penelitian ini, data hasil angket atau kuesioner akan direkap dan dihitung persentase mengenai persepsi wisatawan terhadap wisata kuliner ikan mujair nyat-nyat di Desa Kedisan, Kecamatan Kintamani, Kabupaten Bangli.

\section{Hasil dan pembahasan}

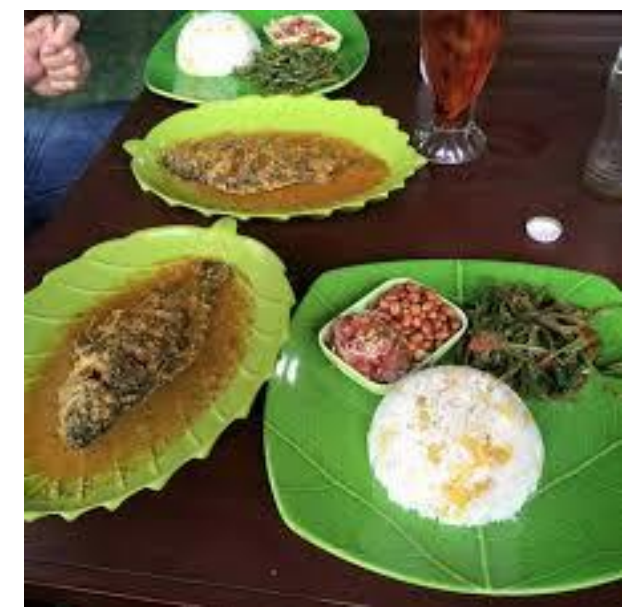

Gambar 1 Ikan Mujair Nyat-Nyat

Sumber: Data olahan hasil penelitian, 2018

Di Desa Kedisan, Kecamatan Kintamani, Kabupaten Bangli, ikan mujair nyat-nyat umumnya dihidangkan dengan sepiring nasi panas, plecing kangkung, sambal matah dan kacang goreng. Istilah Nyatnyat berasal dari kata nyat yang dalam bahasa Bali memiliki arti surut. Kuliner lokal ini diolah dengan cara di goreng setengah matang terlebih dahulu kemudian di nyat-nyat bersama racikan bumbu khas Bali.

Perkembangan kuliner ikan mujair nyat-nyat begitu pesat, hingga tidak hanya dapat dijumpai di Kintamani saja namun, kini sudah tersedia di beberapa warung tradisonal di Bali. berdasarkan hasil wawancara peneliti dengan beberapa pemilik rumah makan ikan mujair nyat-nyat di Desa Kedisan, Kecamatan Kintamani, Kbaupaten Bangli, umumnya dari segi cara pengolahan dan bumbunya tidak ada yang berbeda di daerah lain dibandingkan dengan di daerah asalnya yaitu di Kintamani. Karena memang warung-warung penyedia ikan mujair nyat-nyat di daerah lain langsung mengadopsi cara pembuatan dan juga bumbunya dari Kintamani. Adapun bahan-bahan dan proses pembuatan ikan mujair nyat-nyat dapat dilihat di Tabel 1 dan 2 berikut.

Tabel 1. Bahan-Bahan atau Bumbu Ikan Mujair Nyat-Nyat

\begin{tabular}{|c|c|c|c|}
\hline No & Nama Bahan & & Kuantitas \\
\hline \multirow[t]{3}{*}{1} & Bahan utama & Ikan mujair & 1 ekor \\
\hline & & Air jeruk & Secukupnya \\
\hline & & Minyak goreng & Secukupnya \\
\hline \multirow[t]{5}{*}{2} & Bahan Bumbu & Lengkuas & $15 \mathrm{gr}$ \\
\hline & & Jahe & $40 \mathrm{gr}$ \\
\hline & & Kunyit & $20 \mathrm{gr}$ \\
\hline & & Kencur & $20 \mathrm{gr}$ \\
\hline & & Bawang merah & $80 \mathrm{gr}$ \\
\hline
\end{tabular}




\begin{tabular}{lll}
\hline No Nama Bahan & Kuantitas \\
\hline & Bawang putih & 70 gr \\
& Cabe merah \& cabe rawit & 12 pcs \\
Serai & 1 batang \\
& Bumbu wangen & Secukupnya \\
Terasi & Secukupnya \\
Daun jeruk & 2 lembar \\
Garam \& merica & Secukupnya \\
Santan & Secukupnya \\
& Kaldu & Secukupnya \\
\hline
\end{tabular}

Tabel 2. Proses Pembuatan Ikan Mujair Nyat-Nyat di Desa Kedisan, Kecamatan Kintamani, Kabupaten Bangli

\begin{tabular}{|c|c|}
\hline No & angkah atau Instruksi \\
\hline 1 & $\begin{array}{l}\text { Ikan Mujair dibesihkan kemudian buang sisiknya dan juga buang isi perutnya, lalu sayat-sayat } \\
\text { bagian badan ikan kemudian cuci hingga bersih, selanjutnya rendam beberapa menit pada } \\
\text { campuran air jeruk dan juga kunyit, sambil dipijat-pijat agar bau amis ikan Mujair hilang dan } \\
\text { agar lebih lezat. }\end{array}$ \\
\hline 2 & $\begin{array}{l}\text { Selanjutnya panaskan minyak goreng, kemudian goreng ikan Mujair hingga setengah matang, } \\
\text { angkat lalu tiriskan. }\end{array}$ \\
\hline 3 & $\begin{array}{l}\text { Setelah itu siapkan bahan untuk membuat bumbu nyat-nyat, yang pertama adalah siapkan } \\
\text { ulekan kemudian masukan lengkuas, jahe, kunyit dan juga kenur, lalu ulek kasar, selanjutnya } \\
\text { tambahkan bawang merah, bawang putih, cabe merah dan cabe rawit. Lalu ulek hingga halus } \\
\text { kemudian tambahkan bumbu wangen lalu ulek lagi hingga halus. }\end{array}$ \\
\hline 4 & $\begin{array}{l}\text { Selanjutnya panaskan miyak goreng secukupnya lalu tumis bahan bumbu halus hingga harum, } \\
\text { kemudian tambahkan terasi, daun jeruk, kemudian serai, garam dan merica, lalu aduk-aduk } \\
\text { hingga rata. }\end{array}$ \\
\hline 5 & $\begin{array}{l}\text { Selanjutnya tambahkan pula santan dan juga air kaldu kedalam tumisan tersebut, aduk-aduk } \\
\text { hingga mendidih dan juga mengental. }\end{array}$ \\
\hline 6 & $\begin{array}{l}\text { Selanjutnya masukan ikan Mujair yang telah di goreng sebelumnya, lalu aduk-aduk hingga } \\
\text { bumbu meresap. }\end{array}$ \\
\hline 7 & $\begin{array}{l}\text { Angkat, simpan ikan Mujair pada piring saji lalu siram kembali ikan Mujair diatasnya dengan } \\
\text { bumbu nyat-nyat nya. }\end{array}$ \\
\hline
\end{tabular}

Sumber: Data olahan hasil penelitian, 2018

Berdasarkan pengamatan yang penulis lakukan, diketahui bahwa jumlah rumah makan yang menyediakan kuliner lokal ikan mujair nyat-nyat di Desa Kedisan, Kecamatan Kintamani, Kabupaten Bangli yaitu 5 rumah makan. Adapun kelima rumah makan tersebut antara lain (1) resto apung, (2) warung sari kenali, (3) warung jair nyat-nyat, (4) warung traumas (5) warung makan kedisan. Penulis memutuskan bahwa penelitian ini dilakukan di 3 rumah makan yang ada di Desa Kedisan, Kecamatan Kintamani Kabupaten Bangli, yang sudah mewakili populasi rumah makan yang ada karena sudah melebihi 50\%. Adapun rumah makan yang menjadi lokasi penelitian ini adalah :

a. Resto Apung, restoran ini dinamakan restoran apung karena memang sebagian besar bagian restoran mengapung di atas Danau Batur. Terdapat kurang lebih 5 pondok beratap dan 8 meja outdoor yang berada di bagian restoran yang mengapung ini. Resto Apung yang berada di Desa Kedisan, Kecamatan Kintamani, Kabupaten Bangli ini dapat mengapung berat bantuan tong-tong yang menopang restoran tersebut. Pemandangan dari Resto Apung ini sangat menyejukan dan indah, suasana Danau Batur dan latar belakang pegunungan terutama Gunung Batur yang gagah berdiri di sisi Danau membuat wisatawan selalu betah menghabiskan waktu di tempat ini. Restoran ini juga memiliki penginapan berupa Bungalow yang menghadap ke Danau Batur. Adapun menu jenis makana yang disajikan di Restoran ini adalah makanan Indonesia dengan menu adalannya yaitu ikan mujair nyat-nyat, ikan bakar, dan sebagai penemannya berupa plecing kangkung. Berdasarkan hasil wawancara penulis dengan pemilik rumah makan ini, dijelaskan bahwa kunjungan perbulannya kurang lebih 200 Orang pengunjung.

b. Warung Sari Kenali, warung tradisional ini terletek di pinggir jalan raya Kedisan, Kintamani, Bangli dengan suasana Danau Batur. Warung yang buka mulai pukul 08.00 hingga 19.00 Wita ini, menyediakan menu tradisional Bali dengan menggunakan bahan-bahan yang berkualitas. Warung ini 
memiliki beberapa menu andalan, dan mujair nyat-nyat merupakan satu diantara menu andalan yang ada. Pengolahannya dengan cara dinyat-nyat bersama racikan bumbu tradisional Bali dan sebagai pengharum aromanya digunakanlah tomat. baluran bumbunya yang pas menjadikan hidangan ini kaya akan cita rasa. Warung tradisional ini memiliki 6 meja untuk 2 orang dan 1 meja panjang. Berdasarkan hasil wawancara penulis dengan pemilik Warung Sari Kenali yang berada di Desa Kedisan ini, dijelaskan bahwa jumlah kunjungannya adalah 100 orang pengunjung perbulannya.

c. Warung Jair Nyat-Nyat adalah warung yang terletak di Desa Kedisan, Kecamatan Kintamani, Kabupaten Bangli. Berada di pinggir jalan membuat warung ini sangat gampang untuk ditemukan. Warung Makan ini menyediakan berbagai olahan ikan mujair, salah satunya adalah ikan mujair nyatnyat sebagai menu andalannya. Warung jair nyat-nyat ini buka mulai jam $09.00 \mathrm{~s} / \mathrm{d} 18.00$. harga menu bervariasi, mulai dari 20 Ribuan. Fasilitas yang ditawarkan di warung ini berupa 10 meja dengan kapasitas 4 orang dan 5 meja panjang. Berdasarkan hasil wawancara penulis dengan pemilik Warung Jair Nyat-Nyat yang berada di Desa Kedisan ini, dijelaskan bahwa mayoritas pengunjung disini adalah wisatawan lokal dengan jumlah kunjungan 150 pengunjung perbulannya.

Persepsi wisatawan terhadap wisata kuliner ikan mujair nyat-nyat di Desa Kedisan, Kecamatan Kintamani, Kabupaten Bangli ditinjau dari 2 aspek yaitu faktor internal dan faktor eksternal. Faktor internal yaitu Kualitas Makanan, sedangkan faktor eksternal yang dapat mempengaruhi persepsi wisatawan terhadap ikan mujair nyat-nyat itu sendiri adalah (1) Sumber daya manusia dan pelayanan, serta (2) Hygiene dan sanitasi. Responden telah diberikan lima jawaban dengan rentang skala yang digunakan adalah sangan baik, baik, cukup, kurang, dan sangat kurang dengan diberi nilai dengan skor teringgi 5 poin dan skor terendah 1 poin.

Hal ini dilakukan untuk mengetahui bobot yang diberikan dari responden dengan rician yang ada di Tabel 3 berikut. Data yang dihasilkan dari penelitian ini diperoleh dari penyebaran kuesioner sebanyak 110 buah selama 21 hari mulai dari tanggal 10 Juni s/d 30 Juni 2018.

Karakteristik pengunjung yang datang ke daya tarik wisata kuliner ikan mujair nyat-nyat di Desa Kedisan, Kecamatan Kintamani, Kabupaten Bangli berdasarkan asal daerah dapat dilihat dari Table 3 berikut.

Tabel 3. Karakteristik Pengunjung Rumah Makan Ikan Mujair Nyat-Nyat di Desa Kedisan, Kecamatan Kintamani, Kabupaten Bangli berdasarkan Asal Daerah Periode 10-30 Juni 2018

\begin{tabular}{llll}
\hline No & Asal Daerah & $\begin{array}{l}\text { Jumlah } \\
\text { (orang) }\end{array}$ & $\begin{array}{l}\text { Persentase } \\
(\%)\end{array}$ \\
\hline 1 & Bangli & 46 & 41,81 \\
2 & Gianyar & 36 & 32,72 \\
3 & Buleleng & 7 & 6,40 \\
4 & Badung & 7 & 6,40 \\
5 & Denpasar & 3 & 2,72 \\
6 & Tabanan & 2 & 1,81 \\
7 & Sumatra Utara & 5 & 4,54 \\
8 & Karawang & 1 & 0,9 \\
9 & Australia & 3 & 2,72 \\
Total & & 110 & 100,00 \\
\hline
\end{tabular}

Berdasarkan Tabel 3 dapat disimpulkan bahwa pengunjung yang banyak datang ke daya tarik wisata kuliner ikan mujair nyat-nyat di Desa Kedisan, Kecamatan Kintamani, Kabupaten Bangli berdasarkan asal daerah yaitu berasal dari Kabupaten Bangli sebanyak 46 orang (41,81\%). Hal ini dikarenakan letak daya tarik wisata kuliner di Desa Kedisan, Kintamani berada dalam wilayah Kabupaten Bangli dan jaraknya tidak jauh dari wilayah mereka sehingga pengunjung yang datang ke daya tarik wisata kuliner di Desa Kedisan, Kintamani sebagian besar berasal dari Kabupaten Bangli. Pengunjung yang berasal dari Kabupaten Gianyar sebanyak 36 orang (32,72\%), Kabupaten Buleleng dan Kabupaten Badung masing-masing sebanyak 7 orang (6,4\%), Kota Denpasar sebanyak 3 orang $(2,72 \%)$, dan Kabupaten Tabanan sebanyak 2 orang (1,81\%). Sementara pengunjung yang berasal dari luar Bali beberapa berasal dari Sumatra Utara sebanyak 5 orang (4,54\%), Karawang sebanyak 1 orang $(0,9 \%)$, dan pengunjung asal Australia sebanyak 3 orang (2,72\%). 
Karakteristik pengunjung yang datang ke daya tarik wisata kuliner ikan mujair nyat-nyat di Desa Kedisan, Kecamatan Kintamani, Kabupaten Bangli berdasarkan jenis kelamin dapat dilihat dari Table 4 berikut.

Tabel 4. Karakteristik Pengunjung Rumah Makan Ikan Mujair Nyat-Nyat di Desa Kedisan, Kecamatan Kintamani, Kabupaten Bangli berdasarkan Jenis Kelamin Periode 10-30 Juni 2018

\begin{tabular}{llll}
\hline No & Jenis Kelamin & $\begin{array}{l}\text { Jumlah } \\
\text { (orang) }\end{array}$ & $\begin{array}{l}\text { Persentase } \\
(\%)\end{array}$ \\
\hline 1 & Pria & 63 & 57,27 \\
2 & Wanita & 47 & 42,73 \\
Total & & 110 & 100,00 \\
\hline
\end{tabular}

Berdasarkan Tabel 4 dapat dijelaskan bahwa pengunjung yang banyak datang ke daya tarik wisata kuliner di Desa Kedisan, Kecamatan Kintamani, Kabupaten Bangli berdasarkan jenis kelamin yaitu, jenis kelamin pria sebanyak 63 orang $(57,27 \%)$, dan jenis kelamin wanita sebanyak 47 orang $(42,73 \%)$. Hal ini menunjukan bahwa pengunjung yang datang ke daya tarik wisata kuliner di Desa Kedisan, Kecamatan Kintamani, Kabupaten Bangli didominasi oleh pengunjung berjenis kelamin pria.

Karakteristik pengunjung yang datang ke daya tarik wisata kuliner ikan mujair nyat-nyat di Desa Kedisan, Kecamatan Kintamani, Kabupaten Bangli berdasarkan umur dapat dilihat dari Table 5 berikut.

Tabel 5. Karakteristik Pengunjung Rumah Makan Ikan Mujair Nyat-Nyat di Desa Kedisan, Kecamatan Kintamani, Kabupaten Bangli berdasarkan Umur Periode 10-30 Juni 2018

\begin{tabular}{llll}
\hline No & Umur & $\begin{array}{l}\text { Jumlah } \\
\text { (orang) }\end{array}$ & $\begin{array}{l}\text { Persentase } \\
(\%)\end{array}$ \\
\hline 1 & $<18$ & 26 & 23,63 \\
2 & $18-25$ & 54 & 49,09 \\
3 & $26-33$ & 9 & 8,18 \\
4 & $34-41$ & 11 & 10 \\
5 & $>41$ & 10 & 9,10 \\
Total & & 110 & 100,00 \\
\hline
\end{tabular}

Sumber: Data olahan hasil penelitian, 2018

Berdasarkan Tabel 5 dapat dijelaskan bahwa pengunjung yang datang ke daya tarik wisata kuliner di Desa Kedisan, Kecamatan Kintamani, Kabupaten Bangli didominasi oleh pengunjung berusia muda yaitu umur 18-25 tahun sebanyak 54 orang (49,09\%), dan umur kurang dari 18 tahun sebanyak 26 orang $(23,63 \%)$. Pengunjung yang berusia 26-33 tahun sebanyak 9 orang $(8,18 \%)$, berusia $34-42$ sebanyak 11 orang (10\%), dan pengunjung berusia lebih dari 41 tahun sebanyak 10 orang (9,10\%). Usia 18-25 tahun mendominasi jumlah pengunjung yang datang ke daya tarik wisata kuliner di Desa Kedisan, Kecamatan Kintamani, Kabupaten Bangli karena mereka rata-rata datang beramai-ramai atau rombongan. Karakteristik pengunjung yang datang ke daya tarik wisata kuliner ikan mujair nyat-nyat di Desa Kedisan, Kecamatan Kintamani, Kabupaten Bangli berdasarkan sumber informasi dapat dilihat dari Tabel 6 berikut.

Tabel 6. Karakteristik Pengunjung Rumah Makan Ikan Mujair Nyat-Nyat di Desa Kedisan berdasarkan Sumber Informasi Periode 10-30 Juni 2018

\begin{tabular}{llll}
\hline No & Sumber Informasi & $\begin{array}{l}\text { Jumlah } \\
\text { (orang) }\end{array}$ & $\begin{array}{l}\text { Persentase } \\
(\%)\end{array}$ \\
\hline 1 & Keluarga/teman & 67 & 60,90 \\
2 & Televisi & 6 & 5,45 \\
3 & Koran/majalah & 5 & 4,54 \\
4 & Internet & 30 & 27,30 \\
5 & Lainnya & 2 & 1,81 \\
Total & & 110 & 100,00 \\
\hline
\end{tabular}

Sumber: Data olahan hasil penelitian, 2018 
Berdasarkan Tabel 6 dapat dijelaskan bahwa mayoritas pengunjung yang datang ke daya tarik wisata kuliner di Desa Kedisan, memperoleh informasi dari keluarga/teman sebanyak 67 orang $(60,90 \%)$, diikuti informasi dari internet sebanyak 30 orang $(27,30 \%)$, televisi sebanyak 6 orang $(5,45)$, Koran/majalah sebanyak 5 orang $(4,54 \%)$, dan 2 orang lainnya baru mengetahui setelah mereka sampai di restoran yang ditawarkan langsung oleh pelayan restoran. Sebagian besar pengunjung wisata kuliner di Desa Kedisan, Kecamatan Kintamani, Kabupaten Bangli memperoleh informasi yang langsung diceritakan oleh keluarga/temannya sendiri.

Tabel 7. Jawaban dari Pengunjung Rumah Makan Ikan Mujair Nyat-Nyat di Desa Kedisan yang berkaitan dengan Asal Daerah Periode 10-30 Juni 2018

\begin{tabular}{lcccccccccc}
\hline VARIABEL & Bgl & Gyr & Bll & Bdg & Dps & Tbn & $\begin{array}{l}\text { Smt. } \\
\text { U }\end{array}$ & Krwg & Aus & Total \\
\hline $\begin{array}{l}\text { Keluarga/ } \\
\text { Teman }\end{array}$ & 28 & 19 & 8 & - & 4 & 8 & - & - & - & 67 \\
Televisi & 2 & - & 3 & - & - & 1 & - & - & - & 6 \\
Koran/ & - & 2 & - & 1 & 3 & - & - & - & - & 5 \\
Majalah & 5 & 2 & 1 & 1 & 9 & 3 & 5 & 1 & 3 & 30 \\
Internet & 1 & - & 1 & - & - & - & - & - & - & 2 \\
Lainnya & 110 & & & & & & & & &
\end{tabular}

Sumber: Data olahan hasil penelitian, 2018

Keterangan: $\mathrm{Bgl}=$ Bangli, Gyr $=$ Gianyar, $\mathrm{Bll}=$ Buleleng, Bdg $=$ Badung, Dps $=$ Denpasar, Tbn $=$ Tabanan, Smt. U = Sumatra Utara, Krwg = Karawang, Aus = Australia

Karakteristik pengunjung yang datang ke daya tarik wisata kuliner ikan mujair nyat-nyat di Desa Kedisan, Kecamatan Kintamani, Kabupaten Bangli berdasarkan frekuensi kunjungan dapat dilihat dari Table 8.

Tabel 8 Karakteristik Pengunjung Rumah Makan Ikan Mujair Nyat-Nyat di Desa Kedisan, Kecamatan Kintamani, Kabupaten Bangli berdasarkan Frekuensi Kunjungan Periode 10-30 Juni 2018

\begin{tabular}{llll}
\hline No & Frekuensi Konsumsi & $\begin{array}{l}\text { Jumlah } \\
\text { (orang) }\end{array}$ & $\begin{array}{l}\text { Persentase } \\
(\%)\end{array}$ \\
\hline 1 & 1 kali & 24 & 21,81 \\
2 & 2 kali & 26 & 23,64 \\
3 & 3 kali & 21 & 19,10 \\
4 & 4 kali & 26 & 23,64 \\
5 & Lebih dari 4 kali & 13 & 11,81 \\
Total & & 110 & 100,00 \\
\hline
\end{tabular}

Berdasarkan Tabel 8 dapat dijelaskan bahwa pengunjung yang datang ke daya tarik wisata kuliner di Desa Kedisan, Kecamatan Kintamani, Kabupaten Bangli berdasarkan frekuensi mengkonsumsi kuliner ikan mujair nyat-nyat, yaitu sebanyak 24 orang $(21,81 \%)$ baru 1 kali, sebanyak 26 orang $(23,64 \%)$ telah mengkonsumsi 2 kali, sebanyak 21 orang (19,10\%) telah mengkonsumsi 3 kali, sebanyak 26 orang $(23,64 \%)$ telah mengkonsumsi 4 kali, dan 13 orang $(11,81 \%)$ lainnya telah mengkonsumsi kuliner ikan mujair nyat-nyat lebih dari 4 kali, antara lain 4 orang menjawab sering dan sisanya menjawab 8-10 kali. 
Tabel 9 Frekuensi Kunjungan ke Rumah Makan Ikan Mujair Nyat-Nyat di Desa Kedisan yang berkaitan dengan Asal Daerah Periode 10-30 Juni 2018

\begin{tabular}{|c|c|c|c|c|c|c|c|c|c|c|}
\hline VARIABEL & $\mathrm{Bgl}$ & Gyr & Bll & Bdg & Dps & Tbn & $\begin{array}{l}\text { Smt. } \\
\mathrm{U}\end{array}$ & Krwg & Aus & Total \\
\hline 1 kali & 3 & 5 & - & 3 & 2 & 1 & 5 & 1 & 3 & 24 \\
\hline 2 kali & 3 & 4 & 2 & - & - & - & - & - & - & 26 \\
\hline 3 kali & 5 & 7 & 4 & - & 1 & 1 & - & - & - & 21 \\
\hline 4 kali & 12 & 10 & - & 4 & - & - & - & - & - & 26 \\
\hline $\begin{array}{l}\text { Lebih dari } 4 \\
\text { kali }\end{array}$ & 10 & 2 & 1 & - & - & - & - & - & - & 13 \\
\hline Total & 110 & & & & & & & & & \\
\hline
\end{tabular}

Sumber: Data olahan hasil penelitian, 2018

Persepsi wisatawan yang datang ke daya tarik wisata kuliner ikan mujair nyat-nyat di Desa Kedisan, Kecamatan Kintamani, Kabupaten Bangli dilihat dari faktor internal yaitu segi kualitas makanan antara lain (1) rasa, (2) presentasi, (3) porsi, (4) tekstur, (5) aroma, dan (6) variasi makanan dijelaskan pada Tabel 10 .

Tabel 10 Persepsi Wisatawan terhadap Kualitas Makanan Wisata Kuliner Ikan Mujair Nyat-Nyat di Desa Kedisan, Kecamatan Kintamani, Kabupaten Bangli Periode 10-30 Juni 2018

\begin{tabular}{llllllll}
\hline \multicolumn{2}{c}{ Persepsi } & \multicolumn{3}{l}{ Kotal } \\
No & Variabel & SB & B & C & K & SK & Tol \\
& & 5 & 4 & 3 & 2 & 1 & \\
\hline 1 & Rasa & 155 & 276 & 24 & 4 & - & 459 \\
2 & Presentasi & 65 & 268 & 90 & - & - & 423 \\
3 & Porsi & 95 & 204 & 99 & 8 & 3 & 409 \\
4 & Tekstur & 90 & 240 & 84 & 8 & - & 422 \\
5 & Aroma & 145 & 196 & 78 & 12 & - & 431 \\
6 & Variasi & 55 & 212 & 117 & 10 & 2 & 396 \\
\hline
\end{tabular}

Persepsi wisatawan yang datang ke daya tarik wisata kuliner ikan mujair nyat-nyat di Desa Kedisan, Kecamatan Kintamani, Kabupaten Bangli dari segi faktor eksternal yaitu sumber daya manusia dan pelayanan yaitu (1) cara penyajian makanan, (2) tenggang waktu penyajian makanan, dan (3) keramahan pelayanan dijelaskan pada Tabel 11.

Tabel 11 Persepsi Wisatawan terhadap Sumber Daya Manusia dan Pelayanan Wisata Kuliner Ikan Mujair Nyat-Nyat di Desa Kedisan Periode 10-30 Juni 2018

\begin{tabular}{llllllll}
\hline & & \multicolumn{2}{c}{ Persepsi } & & & & \\
No & Variabel & SB & B & C & K & SK & Total \\
& & 5 & 4 & 3 & 2 & 1 & \\
\hline 1 & Cara penyajian & 65 & 268 & 84 & 4 & - & 412 \\
2 & Tenggang waktu penyajian & 40 & 232 & 114 & 12 & - & 398 \\
\hline
\end{tabular}




\begin{tabular}{lllllll}
\hline 3 & Keramahan pelayanan & 125 & 236 & 54 & 16 & - \\
\hline
\end{tabular}

Persepsi wisatawan yang datang ke daya tarik wisata kuliner ikan mujair nyat-nyat di Desa Kedisan, Kecamatan Kintamani, Kabupaten Bangli dari segi faktor eksternal yaitu hygiene dan sanitasi yaitu (1) kebersihan makanan, dan (2) kebersihan area restoran dijelaskan pada Tabel 12.

Tabel 12 Persepsi Wisatawan terhadap Hygiene dan Sanitasi Wisata Kuliner Ikan Mujair Nyat-Nyat di Desa Kedisan Periode 10-30 Juni 2018

\begin{tabular}{|c|c|c|c|c|c|c|c|}
\hline \multirow{3}{*}{ No } & \multirow{3}{*}{ Variabel } & \multicolumn{6}{|c|}{ Persepsi } \\
\hline & & SB & $\mathrm{B}$ & $\mathrm{C}$ & $\mathrm{K}$ & SK & Total \\
\hline & & 5 & 4 & 3 & 2 & 1 & \\
\hline 1 & Kebersihan makanan & 105 & 116 & 162 & 12 & - & 395 \\
\hline 2 & Kebersihan area restoran & 50 & 136 & 174 & 16 & - & 376 \\
\hline
\end{tabular}

Setelah data terkumpul dari kuesioner penelitian yang kemudian di rekapitulasi, makan peneliti melakukan analisa data agar lebih mudah dibaca dengan skala pengukuran menggunakan skala likert. Rentang skor yang diberikan adalah 5 dan skor terendah adalah 1, Rumus yang di gunakan untuk mengukur jawaban yang di dapat dari kuesioner dengan perhitungan sebagai berikut.

Rata-rata $=\frac{\text { Nilai }}{\text { jumlah Responden }} \times 100$

Persepsi wisatawan yang datang ke daya tarik wisata kuliner ikan mujair nyat-nyat di Desa Kedisan, Kecamatan Kintamani, Kabupaten Bangli dari segi kualitas makanan yaitu (1) rasa makanan, (2) presentasi makanan, (3) porsi makanan, (4) tekstur makanan, (5) aroma makanan, dan (6) variasi makanan dijelaskan pada Tabel 13.

Tabel 13. Persepsi Wisatawan terhadap Kualitas Makanan Wisata Kuliner Ikan Mujair Nyat-Nyat di Desa Kedisan Periode 10-30 Juni 2018

\begin{tabular}{lllllllll}
\hline & \multicolumn{2}{l}{ Persepsi } & & & & \multicolumn{3}{c}{$\begin{array}{l}\text { Rata- } \\
\text { rata }\end{array}$} \\
Variabel & SB & B & C & K & SK & Total & & Ket \\
& 5 & 4 & 3 & 2 & 1 & & & \\
\hline Rasa & 155 & 276 & 24 & 4 & - & 459 & 4,17 & Baik \\
Presentasi & 65 & 268 & 90 & - & - & 423 & 3,84 & Baik \\
Porsi & 95 & 204 & 99 & 8 & 3 & 409 & 3,71 & Baik \\
Tekstur & 90 & 240 & 84 & 8 & - & 422 & 3,83 & Baik \\
Aroma & 145 & 196 & 78 & 12 & - & 431 & 3,91 & Baik \\
Variasi & 55 & 212 & 117 & 10 & 2 & 396 & 3,60 & Baik \\
Nilai rata-rata & & & & & & & 3,84 & Baik \\
\hline
\end{tabular}

Sumber: Data olahan hasil penelitian, 2018

Berdasarkan Tabel 13 dapat dijelaskan bahwa persepsi wisatawan dari segi kualitas makanan wisata kuliner ikan mujair nyat-nyat di Desa Kedisan, Kecamatan Kintamani, Kabupaten Bangli secara umum baik, dengan rentangan nilai tertinggi 4,17 (baik) dan terendah dengan nilai 3,60 (baik). Dari data 
olahan hasil kuesioner diatas diketahui bahwa kualitas makanan yang ada di wisata kuliner ikan mujair nyat-nyat di Desa Kedisan, Kecamatan Kintamani, Kabupaten Bangli dinilai baik, karena rasa makanan yang ditawarkan oleh beberapa rumah makan lezat serta dengan harga yang relative murah dan porsi yang diberikan banyak. Begitu pula dengan presentasi dan variasi makanan yang mendapat nilai baik, yang juga didukung dengan aroma dan teksur makanan itu sendiri.

Persepsi wisatawan yang datang ke daya tarik wisata kuliner ikan mujair nyat-nyat di Desa Kedisan, Kecamatan Kintamani, Kabupaten Bangli dari segi sumber daya manusia dan pelayanan yaitu (1) cara penyajian makanan, (2) tenggang waktu penyajian makanan, dan (3) keramahan pelayanan dijelaskan pada Tabel 14.

Tabel 14 Persepsi Wisatawan terhadap Sumber Daya Manusia dan Pelayanan Wisata Kuliner Ikan Mujair Nyat-Nyat di Desa Kedisan Periode 10-30 Juni 2018

\begin{tabular}{lllllllll}
\hline & \multicolumn{3}{c}{ Persepsi } & & & & \multicolumn{3}{c}{ Rata- } \\
Variabel & SB & B & C & K & SK & Total & rata & Ket \\
& 5 & 4 & 3 & 2 & 1 & & & \\
\hline $\begin{array}{l}\text { Cara penyajian } \\
\text { Tenggang }\end{array}$ & 65 & 268 & 84 & 4 & - & 412 & 3,74 & Baik \\
$\begin{array}{l}\text { penyajian } \\
\begin{array}{l}\text { Keramahan } \\
\text { pelayanan } \\
\text { Nilai rata-rata }\end{array}\end{array}$ & 40 & 232 & 114 & 12 & - & 398 & 3,61 & Baik \\
& 125 & 236 & 54 & 16 & - & 431 & 3,91 & Baik
\end{tabular}

Berdasarkan Tabel 14 dapat dijelaskan bahwa persepsi wisatawan terhadap sumber daya manusia dan pelayanan wisata kuliner ikan mujair nyat-nyat di Desa Kedisan, Kecamatan Kintamani, Kabupaten Bangli secara umum baik, dengan rentangan nilai tertinggi 3,91 (baik) dan terendah dengan nilai 3,61 (baik). Dari data olahan hasil kuesioner diatas diketahui bahwa sumber daya manusia dan pelayanan pada wisata kuliner ikan mujair nyat-nyat di Desa Kedisan, Kecamatan Kintamani, Kabupaten Bangli dinilai baik.

Tata cara berkomunikasi dan prilaku pelayan di rumah makan dinilai baik karena mereka mampu bebricara dengan jelas kepada pengunjung dan juga ramah. Tata bahasa dan tegur sapa pelayan juga dinilai baik oleh pengunjung. Persepsi wisatawan yang datang ke daya tarik wisata kuliner ikan mujair nyat-nyat di Desa Kedisan, Kecamatan Kintamani, Kabupaten Bangli dari segi hygiene dan sanitasi yaitu (1) kebersihan makanan, dan (2) kebersihan area restoran dijelaskan pada Tabel 15

Tabel 15 Persepsi Wisatawan terhadap Hygiene dan Sanitasi Wisata Kuliner Ikan Mujair Nyat-Nyat di Desa Kedisan Periode 10-30 Juni 2018

\begin{tabular}{lllllllll}
\hline & \multicolumn{3}{l}{ Persepsi } & & & & \multicolumn{3}{c}{ Rata- } \\
Variabel & SB & B & C & K & SK & Total & rata & Ket \\
& 5 & 4 & 3 & 2 & 1 & & & \\
\hline $\begin{array}{l}\text { Kebersihan makanan } \\
\text { Kebersihan }\end{array}$ & 105 & 116 & 162 & 12 & - & 395 & 3,59 & Baik \\
$\begin{array}{l}\text { Kestoran } \\
\begin{array}{l}\text { Nilai rata-rata } \\
\text { area }\end{array}\end{array}$ & 50 & 136 & 174 & 16 & - & 376 & 3,41 & Cukup \\
\end{tabular}

Sumber: Data olahan hasil penelitian, 2018

Berdasarkan Tabel 15 dapat dijelaskan bahwa persepsi wisatawan dari segi hygiene dan sanitasi wisata kuliner ikan mujair nyat-nyat di Desa Kedisan, Kecamatan Kintamani, Kabupaten Bangli secara umum cukup, dengan rentangan

nilai tertinggi 3,59 (baik) dan terendah dengan nilai 3,41 (cukup). Kebersihan makanan umum dinilai baik karena memang pihak pengelola rumah makan selalu menjaga dan memperhatikan kebersihan makanan 
itu sendiri mulai dari proses pengolahan hingga dihidangkan. Namun hal itu tidak didukung dengan kebersihan area restoran yang mendapat nilai cukup. Area restoran dinilai masih kurang bersih karena pihak pengelola tidak membersihkannya secara rutin, ditambah lagi dari hasil pengamatan peneliti masih banyaknya lalat di area rumah makan.

Dari data olahan hasil kuesioner diatas diketahui bahwa hygiene dan sanitasi pada wisata kuliner ikan mujair nyat-nyat di Desa Kedisan, Kecamatan Kintamani, Kabupaten Bangli dinilai cukup.

Persepsi wisatawan yang datang ke daya tarik wisata kuliner ikan mujair nyat-nyat di Desa Kedisan, Kecamatan Kintamani, Kabupaten Bangli secara keseluruhan yang dinilai dari 3 variabel yaitu (1) kualitas makanan, (2) sumber daya manusia dan pelayanan, dan (3) hygiene dan sanitasi dapat dilihat di tabel pada Tabel 16 .

Tabel 16 Persepsi Wisatawan terhadap Wisata Kuliner Ikan Mujair Nyat-Nyat di Desa Kedisan, Kintamani, Bangli Periode 10-30 Juni 2018

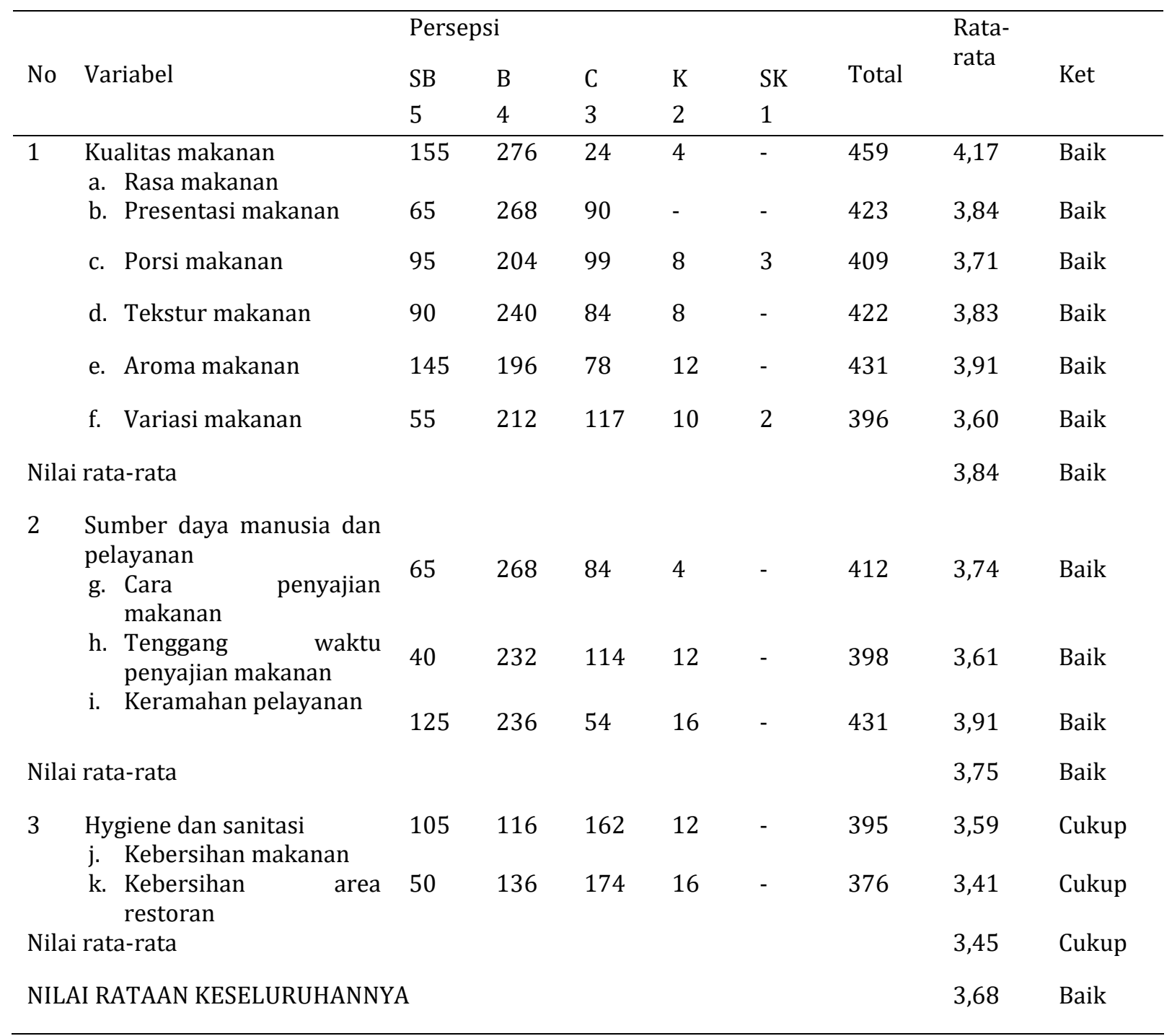

Berdasarkan Tabel 16, dapat dilihat bahwa secara umum persepsi wisatawan terhadap wisata kuliner ikan mujair nyat-nyat di Desa Kedisan, Kecamatan Kintamani, Kabupaten Bangli yaitu sebagian besar responden memberikan penilaian yang positif terhadap variabel kualitas makanan dengan menjawab sangat baik, baik dan beberapa diantaranya cukup. Diantara variabel lainnya, variabel kualitas makanan mendapat nilai tertinggi yaitu 3,84 (baik), ini menunjukan bahwa kualitas makanan pada wisata kuliner ikan mujair nyat-nyat di Desa Kedisan, Kecamatan Kintamani, Kabupaten Bangli memiliki citra positif dimata responden. Hal ini didukung dengan nilai rata-rata rasa makanan dengan perolehan nilai 4,17 (baik) dan yang terendah yaitu variasi makanan yang memperoleh nilai rata-rata 3,60 (baik). Pada 
variabel sumber daya manusia dan pelayanan, sebagian besar responden juga memberikan penilaian yang positif. Dengan nilai rata-rata tertinggi adalah 3,91 (baik) dan terendah 3,61 (baik).

Hal ini menunjukan bahwa wisata kuliner ikan mujair nyat-nyat di Desa Kedisan, Kecamatan Kintamani, Kabupaten Bangli dari segi sumber daya manusia dan pelayanan memiliki citra positif dimata responden. Sedangkan pada variabel hygiene dan sanitasi, responden memberikan nilai baik pada sub variabel kebersihan makanan yaitu 3,59 (baik), namun hal ini tidak didukung dengan kebersihan area rumah makan yang mendapat nilai 3,41 (cukup). Pada variabel hygiene dan sanitasi mendapat nilai akhir 3,45 (cukup), ini dikarenakan menurut sebagian besar rseponden kebersihan area rumah makan dinilai kurang bersih. Hal tersebut didukung dengan hasil pengamatan peneliti dimana peneliti menemukan banyak lalat dan meja yang kurang bersih. Dari hasil pembahasan adapun beberapa hal yang perlu mendapat perhatian khusus agar bisa dikembangkan dan ditingkatkan pada wisata kuliner ikan mujair nyat-nyat di Desa Kedisan, Kecamatan Kintamani, Kabupaten Bangli yakni meningkatkan kebersihan area restoran yang mendapat persepsi cukup.

\section{Simpulan dan saran}

Berdasarkan hasil pembahasan dan analisis data pada bab sebelumnya dapat diambil kesimpulan bahwa persepsi wisatawan terhadap kualitas makanan ikan mujair nyat-nyat di Desa Kedisan, Kecamatan Kintamani, Kabupaten Bangli adalah baik, begitu pula dengan sumber daya manusia dan pelayanannya, namun cukup dari segi hygiene dan sanitasi.

Adapun saran yang dapat peneliti berikan berdasarkan hasil pembahasan, dan analisis data bab sebelumnya yaitu: (1) Perlu diperhatikannya quality control untuk menjaga serta meningkatkan penampilan dan kesehatan makanan (hygiene). Dengan cara pemilihan bahan makanan yang berkalitas, bekerja sama dengan pemasok yang dapat dipercaya sehingga dapat menghasilkan produk ikan mujair nyat-nyat yang berkualitas; (2) Perlu ditingkatkannya pelayanan terhadap pelanggan agar dari yang sebelumnya mendapat penilaian baik menjadi sangat baik dengan membiasakan seluruh staff rumah makan untuk senyum salam dan sapa. Pelatihan kerja juga merupakan hal yang efektif guna meningkatkan kualitas pelayanan. Disamping itu, perlu diberikannya reward kepada staff yang telah bekerja dengan baik sebagai motivasi kerja.

\section{Daftar Rujukan}

Ariyanto.2005. Ekonomi Pariwisata. Jakarta: Gramedia Pustaka Utama.

Ferdinand, Augusty. 2006. Metode Penelitian Manajemen: Pedoman Penelitian Untuk Penulisan Skripsi dan Tesis. Yogyakarta: Pustaka Belajar.

Gitosudarmo, Indriyo. 2000. Manajemen Pemasaran. Yogyakarta: BPFE.

Harsana, Minta dan Maria Tri Widayanti. 2010. Pengembangan Taman Kuliner Codong Catur sebagai Tujuan Wisata Kuliner di Kabupaten Sleman. Politeknik API : Yogyakarta.

Harsana, Minta dan Maria Tri Widayanti. 2010. Pengembangan Taman Kuliner Codong Catur Sebagai Tujuan Wisata Kuliner di Kabupaten Sleman. Politeknik API: Yogyakarta.

Harsana, Minta. 2001. Analisa Pasar Ditinjau Dari Persepsi Wisatawan Terhadap Kuliner di Kabupaten Sleman. Politeknik API: Yogyakarta.

Kotler, Philip. 2009. Manajemen Pemasaran. Jakarta : Erlangga.

Kusdianto, Hadinoto. 1996. Perencanaan Pengembangan Destinasi Pariwisata. Jakarta : UI Press.

Kusmayadi dan Sugiarto, Endar. 2000. Metodologi Penelitian dalam Kepariwisataan. Jakarta: Gramedia Pustaka Utama.

Lumpiyodadi, Rambat. 2001. Manajemen Pemasaran Jasa. Jakarta : Selemba Empat

Marpaung. 2002. Pengantar Kepariwisataan. Bandung: Alfabeta. 
Nasution, M Nur. 2005. Kepuasan Pengunjung dan Pengembangan Fasilitas Agro, Volume 2. Jakarta:Gramedia Pustaka Utama.

Nurjaya, I Wayan. Persepsi Wisatawan Mancanegara Terhadap Potensi Pariwisata di Kelurahan Ubud, Kabupaten Gianyar. Denpasar: Universitas Udayana.

Pendit, S Nyoman. 2002. Ilmu Pariwisata. Jakarta: PT Pradnya Paramita.

Pitana, I Gde dan Gayatri, Putu G. 2005. Sosiologi Pariwisata. Yogyakarta: CV Andi Offset.

Pitana, I Gde dan Diarta, S Ketut I. 2009. Pengantar Ilmu Pariwisata. Yogyakarta: CV Andi Offset.

Sadjuni, Ni Luh Gde Sri. 2006. Thesis Ekspektasi dan Persepsi Wisatawan Terhadap Gastronomi Makanan Bali (Kasus: Pada Restoran Hotel di Kawasan Pariwisata Nusa Dua-Kabupaten Badung). Denpasar: Universitas Udayana.

Sciffnan, Leon. G. dan Kanuk, Leslie. 2007. Perilaku Konsumen. Jakarta: PT. Indeks.

Sugiyono. 2002. Metode Penelitian Administrasi. Bandung: Alfabeta.

Sugiyono. 2009. Metode Penelitian Kuantitatif, Kualitatif, dan R\&D. Bandung: Alfabeta.

Tarwotjo, C. Soejoeti. 2009. Dasar-Dasar Gizi Kuliner. Jakarta: Grasindo.

Umar, Husein. Metodologi Penelitian. Jakarta: Selemba Empat.

www.awalilmu.blogspot.com. Diakes tanggal 12 Maret 2018

www.calyawisata.com. Diakses tanggal 12 Maret 2018

www.heybali.com>makanan-khas-bali. Diakses tanggal 15 Maret 2018

www.longtripmania.org. diakses tanggal 19 Mei 2018

http://metagunawan.blogspot.com/2015/09/teknik-analisis-data.html. Diakses tanggal 3 Juni 2018

www.merlitafutriana0.blogspot.co.id. Diakses tanggal 25 Maret 2018

www.mix.co.id. Diakses tanggal 22 Maret 2018

www.sashylittlekitchen.com. Diakses tanggal 19 Mei 2018

www.scribd.com. Diakses tanggal 10 April 2018 